\title{
The Astronomy Program at the Thacher School
}

Jonathan J. Swift ${ }^{1 *}$, Christopher Vyhnal ${ }^{1}$

${ }^{1}$ The Thacher School, 5025 Thacher Rd., Ojai, CA 93023

*Corresponding author: jswift@thacher.org

\section{Project Description}

The Thacher Observatory, first built in 1965 by the University of California at Los Angeles (PI:

George Abell) (Vyhnal and Swift, 2018), has been recently renovated with a $0.7 \mathrm{~m}$ telescope and a cooled, back-illuminated CCD camera for the purposes of research and education. First light for the renovated observatory was on December 10, 2016, however efforts to build a new curriculum at the Thacher School based on hands-on research began in early 2015.

Now with the facility fully robotic and programmable, student research has accelerated, enrollment in astronomy courses has increased, and student involvement in the campus astronomy club has expanded. The academic program at Thacher currently includes two elective classes as part of the astronomy program: an astronomy seminar and an observational astronomy elective. During the regular academic day a data science class and an astronomy class with research methods are offered. Thacher School also has an independent study program that allows students to do more in-depth work with the observatory. So far, two students have successfully completed independent study terms.

There are currently four different areas of research being actively pursued with the Thacher Observatory: low-mass eclipsing binaries, exoplanet characterization, monitoring of Boyajian's Star, and a small survey for the hypothesized Planet 9. Ongoing efforts to characterize the observatory are also being conducted by students. Topics include telescope optics, camera performance, seeing, sky brightness, and atmospheric extinction.
This program has been built with an underlying belief that education does not have to be isolated from meaningful pursuits, and that education is more potent, lasting and useful when students are learning in pursuit of a higher purpose or goal. These research programs have been designed to serve as these higher purposes that motivate and inspire students to engage with STEM topics at a deep and personally rewarding level.

While the program is still very young, we have already reached many benchmarks toward becoming a fully functioning science and education facility. We have been able to detect stellar binary eclipses and transiting exopolanets such as TrES-3b (ODonovan et al., 2007) shown in Figure 1, and we have obtained a preliminary characterization of our observatory with a zeropoint magnitude of 21.8, and atmospheric extinction of $\approx 0.2$ magnitudes per airmass in the Johnson $V$ band.

\section{References}

ODonovan, F. T., Charbonneau, D., Bakos, G., spá, Á, r., ., Mandushev, G., Dunham, E. W., Brown, T. M., Latham, D. W., and et al. (2007). TrES-3: A Nearby, Massive, Transiting Hot Jupiter in a 31 Hour Orbit.

Vyhnal, C. and Swift, J. (2018). A Century of Astronomy at The Thacher School. Proceedings of the First Meeting of the Robotic Telescopes, Student Research, and Education Conference (RTSRE), June 2017. 


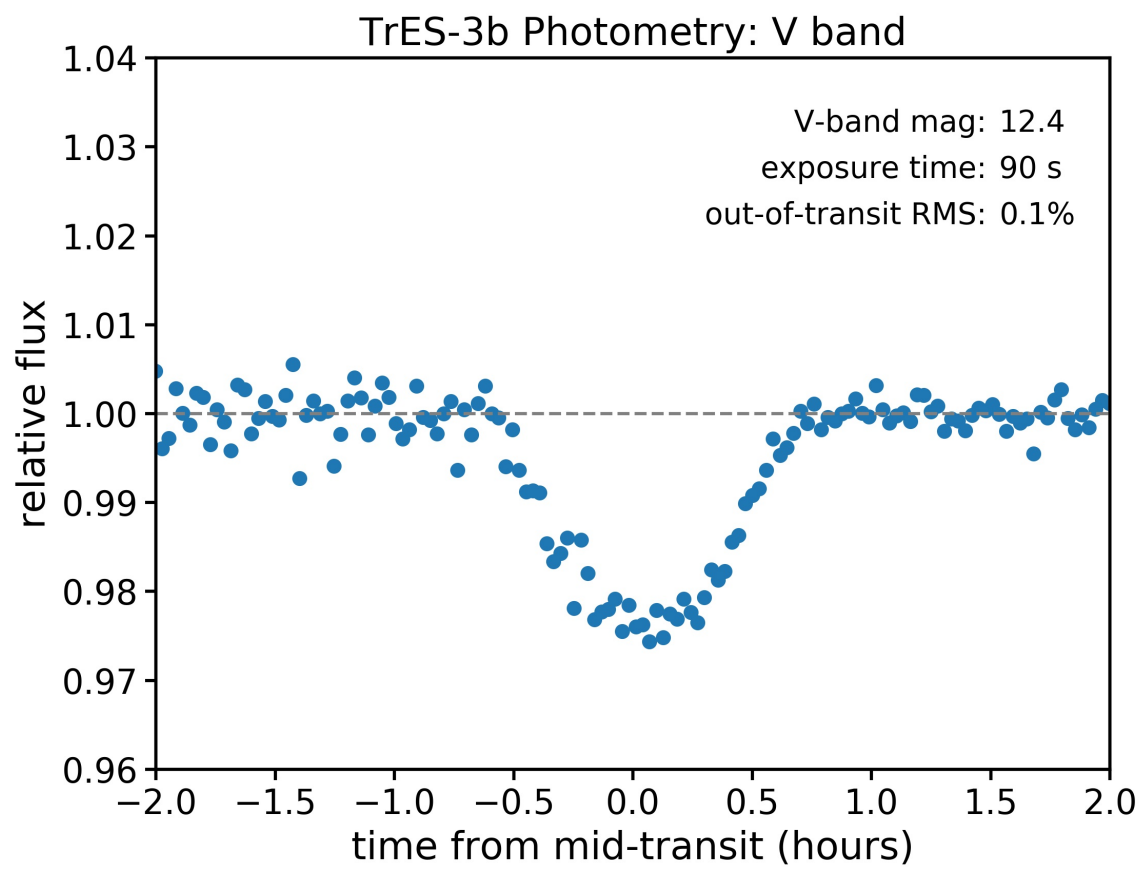

Figure 1. Transit of TrES-3b detected by the Thacher Observatory on UT 23-May-2017. The out-of-transit RMS was measured post transit as the beginning of the observations were at high airmass.

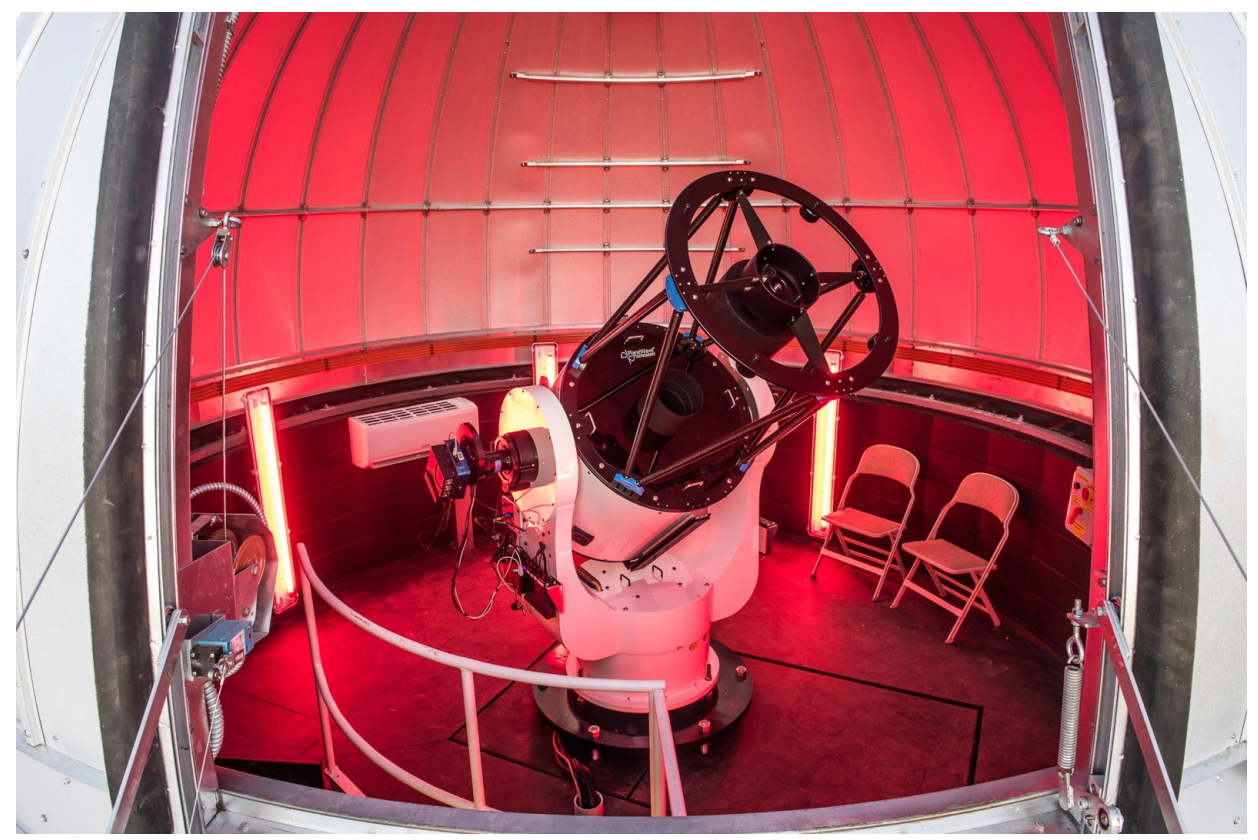

Figure 2. The new PlaneWave CDK-700 in the renovated dome of the Thacher Observatory. First light was celebrated on December 10, 2016. Photo: Paul B. Gardner 